\title{
Eliante in Sardinia: problematic contextualisation
}

\author{
Placido Cherchi^
}

\begin{abstract}
The paper deals with the complex relationship between tradition and modernity inspired by a fundamental essay by Cesare Brandi, Eliante or On architecture? The dialectic between tradition, supported in the Italian art-history panorama at the end of the Sixties by Brandi, and modernity, which found a convinced supporter in Giulio Carlo Argan, was a way of comparing tradition conceived as a cultural mix of various layers but within the same "horizon of meaning", and modernity, the emblem of functional art organically immersed in the dynamics of everyday life. In this perspective the article inquires into the issue of tradition-modernity in the landscape of Sardinia to understand if and to what extent tradition may be considered capable of condensing around it the deep connotations of Sardinian culture.
\end{abstract}

Do you remember Cesare Brandi's dialogue entitled Eliante or On architecture? It came out in 1956, together with another dialogue (Arcadio or On sculpture), and if you trained as an architect at the end of the post-war years, you will certainly have it among your dearest, most worn-out books whereas, if you trained after 1968, you will certainly have come across it often in the bibliography for your courses and will also have been convinced of the need to immediately have it at home on the shelf you kept for important books. In actual fact, it had become a sort of bible-ofmeaning for Italian architects at the end of the nineteen hundreds and was consulted like the oracle each time the problem of deciding between tradition and modernity arose. I remember, moreover, that in my time (I speak of the sixties) it also acted as an essential reference book for literature students taking an art history degree, and I have no doubt that there were many of us who put it on the list of books destined to accompany us to the end. It was not just the stature of the author that imposed it on us in that way: the arguments alone of the individuals conversing and the refined Humanistic balance of their subtle way of talking were enough. As a metaphor summarising the debates then underway, it actually rendered the atmosphere of the moment well, managing to make the protagonists of that false symposium say the things that needed to be said on the important issues raised by advancing modernity.

Behind each individual of the dialogue a true personage of the Italian art-history panorama of the time was

\footnotetext{
Correspondence: maciocco@uniss.it

Deceased

University of Sassari, Sassari, Italy
}

clearly recognisable and, just as Brandi himself had his obvious alter ego in the best-equipped supporter of "tradition", Argan could similarly be identified in the most convinced supporter of "modernity". It was an implicitexplicit way of comparing the viewpoint of a restoration theorist (inevitably tied to the conservationist culture of the Superintendencies) with that of an art historian who had openly espoused the overriding reasons for Gropius' rationalism. The dialectic between the two poles was dominant and, though intelligently mediated by the positions of the other individuals, the pillar of the whole discussion clearly had its foundations in the thread of arguments brought into the field by the counter-figures of the two masters.

If you remember all this, you will also remember that Brandi's arguments in favour of tradition were, however, far from able to appear heavily conservative or able to be reduced tout-court to the anti-modernist deafness of those in charge of protecting the cultural heritage. On the contrary, thanks to the fact that the world of the past had huge quantities of semiological reasons to set against the deculturalising perils of rationalist languages coined by the formal requirements of pure function, they also showed themselves to be more meaningful and captivating than those mobilised from the borders of modernity itself. I would say that from many points of view they managed to have an even stronger, more meaningful flavour of modernity than what we were used to hearing in speeches on the modern trend: at least because the conceptual resources mobilised by Brandi to sustain the idea of

\section{黑 Springer}


tradition were more persuasive and complex than the forms of conceptuality found in the opposing area.

Nonetheless, Eliante did not dwell as much as we would have liked on the actual tradition question. And we future art historians, already contaminated by the virus of anthropologising culturology, ended up preferring the pages of a long article that Guido Morpurgo Tagliabue had dedicated in 1961 to La nozione di "classicità" e il funzionalism moderno (The notion of "classicality" and modern functionalism). In this there was no talk of tradition but the definition given of "classical" was exactly the same as the definition we would have like to find of tradition in Eliante. For Morpurgo classical was "what was organically representative, centrally [...], collectively participated", so that to be defined as classical a work had to be able to establish itself as a place of identification of the choices and interests of a certain society. It seemed to us a perfect definition of tradition meant in the strong sense and we liked a lot the fact that it was not the formal qualities of the work but the degree of organicity and compactness of the societies upholding it which made the classical (i.e. tradition) possible. This meant that the classical (i.e. tradition) did not always.

But what did this Brandian "tradition" have that enabled it to compete with "modernity" for supremacy in appeal? Argan's Walter Gropius e la Bauhaus (Walter Gropius and the Bauhaus) was published in 1951 and no text had yet appeared in Italy that could rival it. The arguments coming from our architectural tradition had been literally overwhelmed by the splendid pages of Argan's unique book, and the followers of "tradition" really found themselves squeezed into a corner by the new "knowing how to see" of this courageous explorer of the "modern trend". All the more since the author did not limit himself to reading the rationalist tendency only from the architectural point of view: the Bauhaus-basin was already on its own account the heart of the modern trends that had dominated the figurative nineteen hundreds, and choosing it as an observation point meant extending on all fronts the discourse on the self-referential tendencies with which avant-gardes had reacted to the "crisis of objectivity" resulting from the First World War. Argan's arguments were frontal and, apart from directing the gaze on the formal values of the new languages, gave a lot of space to the corresponding links between the kind of "doing" worked out on the logics of function, and the requirements gradually emerging in the fabric of the new civil society. It was a way of considering the old problem of the art-society relationship in new terms and wanting functional art organically immersed in the more normal dynamics of everyday life. Just as Gropius had clarified in his theoretical texts on the fundamental lines of Bauhaus-teaching.

This being the situation, it is easy to imagine that one of the internal currents of Eliante was to get back for the "tradition" area the land lost, and to go back with suitable instruments to the disadvantage due to modernity growing out of proportion since the appearance of Argan's Walter Gropius. Of course it was not easy to go back up the slope from the shores of a culture still too heavily laden with classicality and in many ways compromised by the elitist habit of considering art a luxury reserved for the upper classes.

To be able to do so, Brandi walked away from all the forbidden arguments of the die-hards and drew the breadth of his idea of "past-that-counts" from the horizons of anthropology. He, too, in spite of the harshness of the pathways, attempted to argue by the frontal route and tried to achieve an idea of "tradition" almost entirely free from the obligation of micro-definitions. As if in the "tradition-system" perspective or tradition imagined as an organic cultural mix of various layers (but greatly overlapping within the same trajectory of meaning) the overall configurations had greater value than the details collected on Superintendency catalogue forms, and managed to focus more on the spirit of an age, its deep codes. So in a certain way, almost all would be said if we were to say that a "tradition" in this sense was a "horizon of meaning", and that, in being so, it was a remodelling force, able to grant belonging and identity also to things less likely to be appropriately placed. In actual fact, just as the historicists' culture was reflected in each synchronic (or parasynchronic) aspect of a specific historic moment, similarly Brandi's "tradition" stamped its own seal on all things touched by the orbits of its dynamics. It was a case of a dialecticin-progress that knew no grey areas and gave the impression of Hegelian heritage taken up again and enhanced to the maximum heights of historiographic vision cultivated by some historicist-critic of Crocian persuasion. Just to make this clear, think of the meaningfulness the term culture took on in the best pages of Ernesto De Martino's symbolic anthropology.

As a consequence, every artistic fact was always burdened with a high degree of partnership in the spirit of its own time, and a fabric of indissoluble solidarity (positive and negative) bound together the internal logics of their respective ways of entering into history. Hence, an architectural fact - equal to other figurative facts (or other facts that are produced by other ways of "doing", including literary, philosophical, etc.) - was never just a fact of form-style or one of formal coherence entirely contained within the span of some handed-down code: it was also first and foremost - a "total social fact", an "all-place", where, due to abundant confluences, everything always referred back to everything else, according to the meaning imposed by the French school of sociology, from Durkheim onwards. Each bell-tower, let us quote De Martino, was always a "Marcellinara bell-tower", a "centre of the world", symbolically supported by the projections of 
meaning that the community culture had woven round it. Naturally, each outsider's intervention was always placed in an organised context of delicate balances and risked each time upsetting the harmony.

Far from being able to be comprehended like Schelling's black night when all cows are black, this Brandian idea of "tradition" was an articulate response to the voids in historicity that accompanied Argan's genesis of modernity, and its extraordinary fascination - or at least the aspect that caused us the dilemma between Walter Gropius and Eliante - lay perhaps in this.

But - careful - an idea of tradition like this required the existence of a historical situation able to give it support. In a certain sense Brandi had an easy task introducing it into a situation like the Italian one, dominated despite the pre-unification fragments - by almost uninterrupted lines of continuity. The continuity assured by the Church had always reabsorbed the political discontinuity suffered by mainland Italy, and in spite of the inequality between north and south it was simple to induce people to speak of the Italian world as one of organic societies. It was easy for architecture here to pass off as really being a "total social fact" and for the architectural tradition to present as an extensive, unfurled "horizon of meaning" able to express it at a highly organic level. It was easy, that is, to speak of traditional architecture or an architectural tradition organically immersed in the structuring of community culture. But how would the terms of this interpretative approach have been placed in the face of a historical situation of a completely different type? Would they still have been able to keep themselves on the same trajectory or would they have had to adapt to the symbolic logics promoted each time by different dynamics?

Moreover - once more, careful - precisely this adoption of tradition as a "horizon of meaning" implied that in the same tradition-mesh a difference should be introduced between the traditional aspects that really had managed to work fully along the line of such meaningfulness, and the traditional aspects that, on the contrary, had not been rewarded with an equal capacity for being assimilated and acknowledged as resonant with a common tradition. In the case of architecture, for example, one only had to go beyond the Italian sphere to realise that, below and above certain residual areas, things might not be situated at the height of this meaningfulness perceived by Brandi, and that the palm of "horizon of meaning" might be assigned much more to other channels of tradition than the architectural tradition proper.

These were not unessential issues. Both points seriously challenged the theoretical capacity of Brandi's arguments and had the power to confine them to the limited spaces of certain specific ambits. This matter could not, of course, reduce the positive nature of the appreciation that needed to be reserved for this interpretative force, but it became unavoidably noticeable that we were obliged to consider it a largely unusable proposal when we were dealing with different landscapes from those that gave a historical background to the pages of Eliante. Undoubtedly, after the initial enthusiasm, confusion had begun to arise and rethinking to move forward. Eliante continued to be an extraordinary lesson in Humanism but it certainly regressed somewhat on the plane of having been a bible of meaning.

On the other hand, precisely on the question of meaning, the need was becoming rather urgent here at home to introduce some important distinctions in the arguments usually put forward on the degree of traditionality of things belonging to our mesh of traditions. That bible of meaning was an allusion, a reference frame that could not be circumvented; it nonetheless needed without fail to be gone through again and rediscussed from a less Italian viewpoint and in the light of attention more in harmony with the particular qualities of our specific situation.

If these, in principle, were the background to our approach, at this point we could abandon the objective lines of the dialogue and begin asking ourselves how Eliante would have acted if, instead of dealing with the landscape of Italian culture, he had been dealing with the landscape of Sardinian culture. The real subject of our discourse, in actual fact, was not the arguments being left behind but the contradictions those arguments would give rise to in the event of an attempt to verify the situation at home. When, from the start, a title was sought for this piece, the intention of ferrying Eliante to Sardinia was already present and prompted the idea of inquiring into the tradition-modernity issue - from a different standpoint from that of Brandi.

Here, at home, it was indeed architecture - or the subject favoured by the Brandian dialogue - that balked more than anything else at the idea it could be considered an "all-place" or a "horizon of meaning" able to condense around it the deep connotations of our culture. Whether we referred to the examples of civil architecture most celebrated for "sardità" (quality of being Sardinian) (such as the lolla campidanese [Campidano husk] or the stazzo gallurese [Gallura cottage]), or to the examples of cult architecture dotted across vastly different areas of the island (such as the Pisan Romanesque churches present all over our territory), it could certainly not be denied that we were referring to a phenomenology of construction long consolidated as tradition. But many doubts existed as to whether their traditionality could have the same type of symbolic meaningfulness as that Brandi attributed to the traditionality of his monuments.

It was unlikely that culture originating in and lasting through anti-classicality could be identified without reserve in the substantially classical features of the architectural 
buildings coating it. On the contrary, the impression slowly developed that since late antiquity times (or perhaps even earlier) the Sards had not enjoyed inhabiting the angular Euclidean shapes of buildings that rose on plans with a classical structure. And these, even in their elementary nature, were the shapes of the dwelling models that had begun to predominate in the fabric of places chosen as collective habitats. In opposition to the urban types of the lolla or the micro-agglomerates of the stazzo, the cubones [shepherd's huts], present in their turn everywhere in the rural areas (including those immediately adjacent to urban centres), seemed to speak of nostalgia for circular elements, cupolas, volumetric solutions nearer to the existential spatialites of the nuragic village. They seemed to implicitly suggest the need to loosen, at least during the hours in the country, the fossilising proxemics imposed by the archetypal geometry of that classicality that, after the example of the hegemony of the moment, had already covered the territory. They seemed to speak, that is, of a flight or inclination for flight able to make a symptom, if nothing else, of restlessness. At least going to the cubone could mean going back to comfortable everyday clothes after the plaster casts imposed by clothes for dies nodidas (Sunday best).

Neither could the argument have been any different, of course, regarding the Pisan-Romanesque architecture of our churches, also long worshipped in all manner of common speech, as an eminent example of "sardità". Here, too, in fact, it was necessary to think of the need to take back to more real terms the idea of "doing", highly representative and organically immersed in the symbolic horizons of our communities. Not only because it was a kind of architecture literally conceded and implicitly imposed by external hegemonic cultures, but also because their indisputable classicality went quite against the anti-classical preferences present at all levels in the choices of taste dominant in most of the expressive forms of our material culture.

And, starting from afar, we were anti-classical in many things. From the anti-volumetric and anti-perspective planarity of pictorial representations, to the morphemic stylisation of iconic achievements, and to the frequent elusion of the anthropomorphic or the organic, we had born witness for some time, and in an unsuspectedly wide range of aspects, to our oriental, Byzantine and Islamic, ancestry. Namely, for some time we had been speaking the aniconic languages triggered by the historic processes that had led to the dissolution of the classical image. In this we were undoubtedly linking up with the stylisation and aniconism of our deepest hinterland. To be convinced of this without effort, it would have sufficed to dwell a little on the decidedly Byzantine- and Islamicinfluenced quality of the dominant anti-form in our handicraft products: textiles, first of all, and wood and the ceramic sector a little later. The almost complete absence of a narrative syntax to organise in a tale the parataxis of the endless repetition of a certain morpheme (usually more geometric than iconic) was already on its own account a clear hint of anti-classicality. It is difficult to have this type of imagination flow into the canons of architectural "creation" renowned as ours.

Altogether, the doubts that might then have been nurtured on the possibility of transferring onto Sardinian territory the idea of architecture that could be read as an "all-place" were not negligible. Eliante, himself, after a few initial glances over the surroundings at his arrival point, would have changed his mind about unpacking his bags.

On the other hand, to persuade us of the fact that the doubts of those times were not unfounded, in more recent years (from 1995 onwards) the theoretical acquisitions were added that I had achieved in the research I was carrying out on the verbal structure of the Sardinian language. We are a people that use the indicative little or are used to speaking as if its existence were almost unknown. We prefer to entrust the definition of our way of relating with reality to the hypothetic-dubitative triangulations of the conditional and the subjunctive, mainly because we tend to measure the reliability of what is apparent by using the yardstick of its paradigmatic 'should be'. It is known that when I speak or write, the indicative is the more direct, frontal way of speaking the language I speak and that, on the contrary, the subjunctive and the conditional are more indirect, transversal ways of the mental-linguistic posture I can adopt in relating with those different from me and with the world. It is not irrelevant that when faced with an object (for example, a glass), the Sard who really speaks Sardinian will never say "This is a glass", but "This should be a glass" (Custa diat essere una tazza): it means that his forma mentis immediately imposes a distancing, doubting attitude on him, rather than a simple, frontal assertive attitude, somehow diverging from a normal confident exchange with reality. It means that if, on the plane of objects, he manages to be sufficiently rich in ontological and designative assurance, on the plane of reality concerning action, on the other hand, it transpires that he is incredibly dilemmatic and inquiring. As if a form of split conscience were forbidding him to confidently immerse himself in his own reality or prevented him from feeling it entirely his. Or as though he were systematically opposing the world of appearances with the world of "should be". All this does not have a mysterious genesis. It is perhaps the scarred outcome of wounds inflicted on the deep tissues of our internal physiognomy by the repeated expropriations of the world, subsequent to the great deal of external domination that came our way.

Now, if the memories of the classical world school passed on to us are not spoilt by rough approximations 
and really are memories that gravitate a great deal around the indicative pole (beginning with the highly anthropomorphic-determinative nature of Quintilian Latin or the muscular vocation of Roman ethics), it is impossible not to notice how our forma mentis gravitates instead around poles of a very different kind. Apart from opening up much more to the symbolic and self-referential dimensions, it willingly inhabits the paradigmatic regions of "should be" with a strong inclination for making the hypothetical periods that can be constructed on more elementary "possibles" also become hypothetical periods of unreality. And just as the mentally-organised contents of the allusive are no less consistent than the perceptive contents put into the field by the phenomenologies of what is apparent, in the same way, to affirm via the contrary (think of the paradoxes of antiphrastic sayings) is no less consistent than the incontrovertible truth of any $2+2=4$. Except that several layers of nuances and aside winks have to compensate for the silence of the unsaid or the side-stepping practice of saying things the other way round.

Is it possible to imagine a forma mentis more anticlassical than this, however? That is to say, can we imagine that a spiral-shaped logos like the one we are speaking of could have been recognised in an otherness so different and could have entered into harmony with lifestyles moulded by the binary logics of spatiality fundamentally based on the volumetric developments of the square? If the balance of the square is the balance of the archetypal form that mostly resembles the balance of a direct type of specular frontality, always privileged as an anti-chaos symbol (think of how the verb "frame" has lasted in the Romance languages with its meaning "bring back to order"), then I believe we should strongly disagree with the idea that a culture like ours, so immersed in the problem-causing subtleties of the conditional mode, could have felt itself expressed-represented by the constructive choices of a handful of cultures accustomed to explaining the world through the indicative mode. Even if we wish to admit that through the centuries of almost two millennia, adoption processes and acculturation outcomes of some importance may have been able to take place - we are obviously speaking of processes sufficient to make things become our tradition that are very foreign to the people at home- it is unthinkable to speak of a "Sardinian" architectural tradition configured in this way, using the same scale of values used by Brandi for the mainland architectural traditions. Not only because, apart from the Hispanic-Savoy academies, the anti-classical features of our figurative culture obstinately resisted the obligation to give an adequate context to the Euclidean language of the architectural models landing on these shores, but also (and above all) because up until the end of the last war the mindset developed by our people never loved the worldviews transmitted under domination.

Of course, if the architectural tradition existing here is far from able to be considered sufficiently abundant in "sardità" or sufficiently representative of the worthy elements that best express our specific case, the problem remains of knowing in which aspect of the Sardinian traditions "tradition" encounters that level of "horizon of meaning", of "all-place", that Brandi opposed to the "non place" character of the modern positions backed by Argan.

And we ought to be aware, first of all, that from the last war onwards, the objective conditions began to diminish also in Sardinia that once enabled some "place" to become a "place" of vast collective identification. Here, too, like elsewhere, for some time that pulverisation of social universes has penetrated, which the capitalist division of labour had injected, via the dynamics of relative surplus-value, into the fabric of communities still tied to handicraft production methods, and here, too, like elsewhere, the standardisation of extended consumerism has been accompanied by the diversified proliferation of sociological islands that hardly communicate with each other. Even the communities of the pastoral and peasant worlds, always in the front line of resistance against the capitalist way of production, ended up accepting its logics, losing their difference of societies balking at the corrosive persuasiveness of the division of labour. Actually, at least as regards the survival of the world we knew, tradition as a "horizon of meaning" has stopped being a possibility.

We also need to be aware of the fact, however, that perhaps at home the "horizons of meaning", despite the existence of the objective conditions that would have allowed them, might not have found - nor in the past of which we still have memories - the most suitable "places" of coagulation to foster their sensitive objectivisation. The forma mentis to which language bore witness has always been too subtle and fleeting for any non-linguistic semantics to be able to translate it without loss and make it become "place". Or for the actual word arts (I am thinking of the things most labelled as tradition: poetry, improvised poetry, oral narrative, etc.) to manage to reach its height and contribute to making its worth widely available. In their being incurably ill with Greek-Roman mythology and Arcadia, the latter have in actual fact always ended up imprisoning the pluri-stratified richness of our forma mentis in the almost unbearable plaster casts of their literary displays, and have always ended up reducing the anti-classical patrimony of sa limba to manner, rather than tradition. Perhaps music alone has managed to really express this internal physiognomy and really be a "place" of extensive convergence. Only music and, of course, beside it, the auratic aspects of language itself.

We are speaking, however, of two possibilities of the past difficult to trace in the present. The Sardinian 
language, as is known, has been reduced to a corner and the music using it is not much better off. Forced into a wretched life, consisting of ebbing waves of inertia and embalming maquillages of poor cultural significance, it has been overturned by shocking levels of electronic megasound of imported music, and even the most committed independence-seeking line-ups in defence of the "specific situation" are organising their parties without remembering its existence.

At this point one might naturally wonder if in our future some "horizon of meaning", some "all-place", might be born, able to emerge as a place of condensation of our innermost folds. To ask ourselves this would be the logical consequence of the thread of argument we have pursued, but it is possible that, put in these terms, the question we are facing has not been posed properly. It is possible, that is, that we are still in a process underway and that the modernity that is changing us might manage to give satisfactory answers to some processes of the past that have remained without results. The basic impression is, in effect, that a certain circle with a macro-historic range has begun to close and that discourse that would not have been possible in Brandi's times is becoming more and more viable. Of course, the strange, and also paradoxical, thing is that it would be precisely the architecture Brandi challenged that would close it.

This thesis is undoubtedly bold, but I do not think that supporting it would mean to dangerously lean over the chasm of some heresy. Morpurgo-Tagliabue was already of a similar opinion, though on different planes, in the last part of the work we quoted above. Except that, if Morpurgo took modern functionalism (the rationalist kind dear to Argan) as an example, in the case of Sardinia all the Euclidean-quantitative traces left unscathed in rationalism would need to be skipped and reference made above all to the modern trends born in the wake of research devoted to things other than function. The reason for this difference becomes transparent if we agree to go back for a moment to the issue of our forma mentis and once again set our gaze on the nature of some of its folds.

Let us dwell a little longer, then, on our native langue. Does it not seem to you that in its anti-classicality and its being more a child of meta-sense than logics, it has many things in common with certain basic assumptions of the languages broadcast by the semantic changes of the early nineteen hundreds? For example, with the fading out of anti-form that gave place to the more asyntactic and excessive abstractionism of the informal period? Or with the deconstructive airiness of some architectural experiences born on the wave of "organic" poetics? Does it not seem to you, that is to say, that between the marked self-referential nature of our linguistic tendency and the dominant self-referentiality overarching the modern trends less curbed by binary obligations, there is a slight affinity, a secret relationship in outlook? When we were students Gaudís anti-academic transgressions had begun to make us think so (the story-telling gratuitousness of his chimneys and of the Sagrada Familia greatly fascinated us); later Mirò's walls continued to make us think so, dotted casually around Klee's Villa $R$ or among the hypothetical districts of his lagoon towns; nowadays, looking at something like the Guggenheim in Bilbao, we get the old fantasies returning and it is difficult for us to resist the temptation of some bold analogy. Even less do we manage to resist the idea that, if we wished to give an architectural shape to our forma mentis, Frank Gehry's invention might easily be considered the opérateur de connaissance we were looking for or the successful translation of the hypotheses that were buzzing through our heads when we confusedly thought of the possibility of letting our internal world inhabit something modern, able to recall the spatial choices of our far-off hinterland. More than Gaudís or Klee's things, Gehry's Guggenheim seems to have been born from a sort of divinatory ear for forgotten worlds and concealed visions. Including those that speak to us at a meta-sense level in the objectivising fabric of our words. It remains to be understood, of course, if it is us to be recognised or if it is our ancient modernity to optatively be recognised in this form of current modernity. If the first hypothesis conflicts with any reasonable calculation of what is historically compatible (and whenever did Gehry worry about our forma mentis?), the second links up instead with the matter of the macro-historic circle that has begun to close. But the space available to us is full: we shall postpone the chance to speak of this to another occasion. An ancient modernity of the Sards has been spoken of on various occasions (not here) and there have been attempts, 2here too, to see the decidedly modern character of the figures recurring in the fabrics of our material culture.

\section{Consent to publish}

Franca Maria Falzari, wife of the deceased Placido Cherchi, has consented to the publication of this article in City, Territory and Architecture, in collaboration with Editor-in-Chief Prof Giovanni Maciocco, who has acted as the correspondence contact on her behalf.

\section{Authors' information \\ Author was deceased at the time of publication.}

\section{Acknowledgements}

The decision to publish the article by Placido Cherchi was taken by virtue of interest in the topic, the quality and the content as well as the prestige of

the scholar who holds a rich biography of publications, always accompanied by an insightful and up-to-date bibliography. The premature death of Placido Cherchi impeded him, however, from inserting the bibliography into his last article. It is my conviction that he would have completed it with his habitual seriousness, pertinence and professionalism had he the opportunity.

Giovanni Maciocco Editor-in-Chief, City, Territory and Architecture

Received: 4 February 2015 Accepted: 4 February 2015

Published online: 28 May 2015 